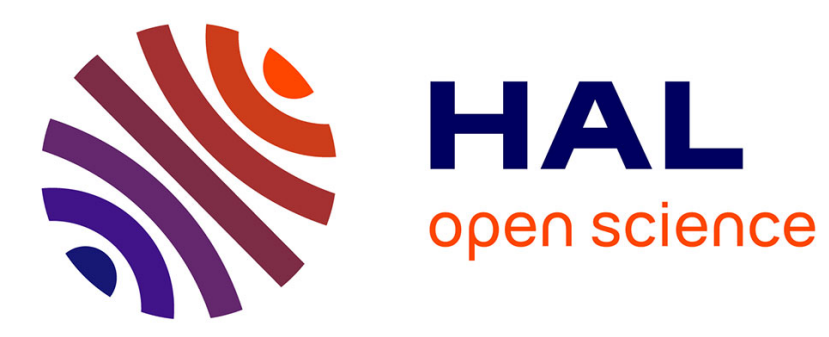

\title{
Tracking an ion complexing agent within bilayers
}

Amélie Banc, P. Bauduin, Olivier Diat

\section{To cite this version:}

Amélie Banc, P. Bauduin, Olivier Diat. Tracking an ion complexing agent within bilayers. Chemical Physics Letters, 2010, 494 (4-6), pp.301-305. 10.1016/j.cplett.2010.05.087 . hal-00546703

\section{HAL Id: hal-00546703 \\ https://hal.science/hal-00546703}

Submitted on 15 Dec 2010

HAL is a multi-disciplinary open access archive for the deposit and dissemination of scientific research documents, whether they are published or not. The documents may come from teaching and research institutions in France or abroad, or from public or private research centers.
L'archive ouverte pluridisciplinaire HAL, est destinée au dépôt et à la diffusion de documents scientifiques de niveau recherche, publiés ou non, émanant des établissements d'enseignement et de recherche français ou étrangers, des laboratoires publics ou privés. 


\title{
Tracking an ion complexing agent within bilayers
}

\author{
A. Banc and P. Bauduin and O. Diat ${ }^{1}$ \\ ${ }^{1}$ Institut de Chimie Séparative de Marcoule, UMR 5257 \\ (CEA/CNRS/UM2/ENSCM), BP 17171, 30206 Bagnols sur Cèze, France
}

\begin{abstract}
In this Letter, we show the benefit of using a lyotropic lamellar phase as a self assembled model system to investigate the distribution of a lipophilic molecule at a hydrophilic/hydrophobic interface. For complexing agents used for ion transfer in liquid/liquid extraction it is essential to determine their interfacial activity. Coupling scattering and spectrometry techniques, we show that it is possible to determine accurately the amount of this type of molecule at the interface.
\end{abstract}

\section{INTRODUCTION}

Investigation of localization, partitioning and orientation of molecules (small molecules [1], peptides [2], membrane proteins [3]...) inserted into bilayers is ubiquitous in membrane related phenomena, especially for biological issues. Vesicles and lyotropic lamellar phases $\left(L_{\alpha}\right)$ are good model systems for membrane and are usually probed by various techniques such as NMR [1], fluorescence quenching [4], ATR-FTIR [5], X-ray scattering [6], molecular dynamics [7] etc. The advantage of $L_{\alpha}$ is the ability to confine host molecules into numerous stacked bilayers at the thermodynamic equilibrium and among which the interactions are very sensitive to weak effects [8]. Herein, we precisely characterize the insertion of a lipophilic complexing agent within a lamellar phase of surfactant using a simple combination of polarized light microscopy, X-ray scattering and $\mu$-Raman spectroscopy experiments. This first study will allow later to track the complexing agent within the organic components as a function of interacting ions diluted in the aqueous phase. The host molecule here is $N^{1}, N^{3}$-dimethyl- $N^{1}, N^{3}$-dibutyl-2tetradecylmalonamide (DMDBTDMA), generally studied as extractant to separate minor actinides from high level radioactive liquid wastes by liquidliquid extraction processes in the nuclear industry [9]. The lamellar phase is made with a non-ionic surfactant (to get a neutral host system for future studies with interacting ions) taken in the alkyl poly(ethylene oxide) series, pentaethyleneglycol dodecyl ether $\left(\mathrm{C}_{12} \mathrm{E}_{5}\right)$ (Fig.1). $\mathrm{C}_{12} \mathrm{E}_{5}$ is a well-known surfactant which forms a fluid lamellar phase at room temperature [10, 11]. This liquidcrystalline system was formulated with the aim to study the interfacial behavior of DMDBTDMA which is, at present, insufficiently known to develop precise predictive models of the solvent extraction process $[12,13]$. The evolution of the lamellar phase boundary within the phase diagram, as well as the lamellar structural parameters were analyzed and confirm the insertion of extractants into membranes. Then, for the first time, $\mu$-Raman experiments were performed on oriented lamellar phase domains to probe the orientation of the confined host molecules. The whole result enables to identify and quantify equilibrium between

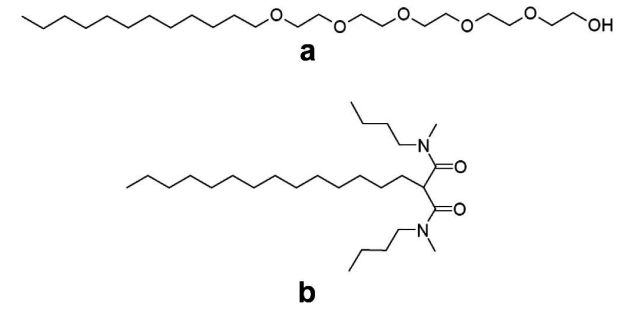

FIG. 1: Molecular structures of $\mathrm{C}_{12} \mathrm{E}_{5}$ (a) and DMDBTDMA (b).

extractants involved in the interfacial activity and those embedded within bilayers as an oily component.

\section{EXPERIMENTAL SECTION}

$\mathrm{C}_{12} \mathrm{E}_{5}$ was obtained from NIKKO Ltd. (high purity grade $>99 \%$ ) and used as received. DMDBTDMA was obtained from PANCHIM and was purified on an alumina column to eliminate traces of surface active impurities. $\mathrm{LiNO}_{3}(1 \mathrm{M})$ solution was prepared using ultrapure water (resistivity $18.2 \mathrm{M} \Omega \mathrm{cm}$ ) and $\mathrm{LiNO}_{3}$ salt (reagent grade) from Sigma. Samples were formulated adding the salted solution to a premix of $\mathrm{C}_{12} \mathrm{E}_{5}$ and DMDBTDMA. Sample were homogenised with a succession of centrifugations and were left several days at $25^{\circ} \mathrm{C}$ to reach equilibrium.

SAXS measurements using Mo-radiation $(\lambda=0.71 \AA$ 을 were performed on a bench built by XENOCS. The scattered beam was recorded using a large online scanner detector (diameter: $345 \mathrm{~mm}$, from MAR Research) located at $750 \mathrm{~mm}$ from the sample stage. A large $Q$ range $\left(2 \times 10^{-2}\right.$ to $\left.2.5 \AA^{-1}\right)$ was covered thanks to an off centre detection. The collimation is applied using a $12: \infty$ multilayer XENOCS mirror (for Mo-radiation) coupled to two sets of FORVIS scatterless slits [14] providing a $0.8 \times 0.8 \mathrm{~mm}^{2} \mathrm{X}$-ray beam at the sample position. Pre-analysis of data was performed using FIT2D software, taking into account the electronic background of the detector (the flatfield is homogeneous) and the empty cell subtraction. The scattered intensities are expressed versus the magnitude of scattering vector $Q=$ $(4 \pi / \lambda) \sin (\theta / 2)$, where $\lambda$ is the wavelength of incident 
radiation and $\theta$ the scattering angle. Experimental resolution was $\Delta Q / Q=0.05$.

Microscopic observations were performed on a ZEISS Axio Imager A1m microscope equipped with crossed polarisers. In order to establish the phase diagrams, temperature scan was realised with a stage temperature LINKAM controller.

Raman spectra were recorded at room temperature on a LabRAM Aramis confocal $\mu$-spectrometer from Horiba Jobin Yvon, using a $532 \mathrm{~nm}$ laser. An Olympus BX41 microscope equipped with a $50 \times$ objective was used to focus the laser beam on oriented domains preliminary located by polarized light microscopy. We carried out a preliminary study of the anisotropy of the Raman tensors characteristic of our samples collecting polarized Raman spectra of the isotropic components of the sample: the $1 \mathrm{M} \mathrm{LiNO}_{3}$ solution and the preliminary mixture of DMDBTDMA and $\mathrm{C}_{12} \mathrm{E}_{5}(80 / 20)$. Bands associated with isotropic Raman tensors display the same intensity in parallel (VV) and crossed (VH) polarizations contrary to anisotropic ones. We have observed that elongation vibrations $(\mu)$ of $\mathrm{CH}_{2}\left(2900 \mathrm{~cm}^{-1}\right), \mathrm{OH}$ (around 3400 $\left.\mathrm{cm}^{-1}\right), \mathrm{C}=\mathrm{O}\left(1647 \mathrm{~cm}^{-1}\right)$, and $\mathrm{CO}$ (810 and $840 \mathrm{~cm}^{-1}$ ) are characterized by anisotropic Raman tensors when at $1300 \mathrm{~cm}^{-1}$, a vibration mode associated to an isotropic Raman tensor is observed. This vibration mode was later used to normalize the intensity of all our spectra after their baseline correction with the spectrometer associated software.

For microscopic observations and acquisition of Raman spectra, flat capillaries (thickness $50 \mu \mathrm{m}$ or $200 \mu \mathrm{m}$ ) were filled with the samples and sealed on glass slides with a UV curing adhesive (Norland Optical Adhesive 81).

\section{RESULTS AND DISCUSSION}

\section{Scattering experiment}

Mixtures of $\mathrm{C}_{12} \mathrm{E}_{5} / \mathrm{DMDBTDMA}$ (up to $70 / 30 \mathrm{M}$ ) were hydrated with a $1 \mathrm{M}$ brine, to be in the ionic strength range applied in extraction systems [15]. In this work, $\mathrm{LiNO}_{3}$ salt was chosen, being a commonly used anion, and $\mathrm{Li}^{+}$being a non complexant cation for the extractant. The monophasic lamellar domain for various mixtures was determined as function of $\mathrm{C}_{12} \mathrm{E}_{5}$ /DMDBTDMA weight fraction $(\phi)$ and temperature, using polarized light microscopy. In Fig. 2a, the $80 / 20$ system is compared with the one of the $100 / 0$ also hydrated with $1 \mathrm{M} \mathrm{LiNO}_{3}$, which is similar to the pure $\mathrm{C}_{12} \mathrm{E}_{5}$ /water system. It appears that the addition of DMDBTDMA shifts the lamellar domain to lower membrane fractions and lower temperatures. It is consistent with a modification of the spontaneous curvature of the aggregates towards water. It can be explained with the packing parameter $(\mathrm{P})$ concept $[16]$. $\mathrm{P}$, which character-
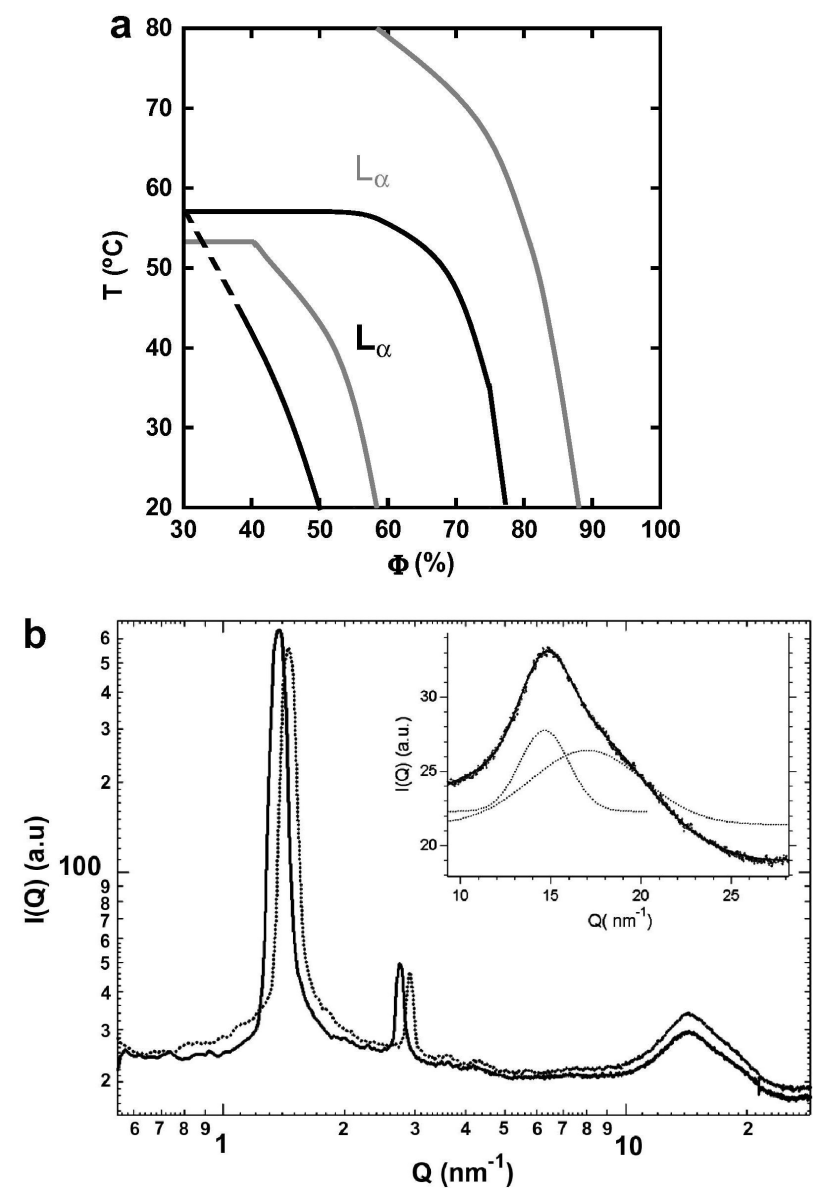

FIG. 2: Comparison between $\mathrm{C}_{12} \mathrm{E}_{5}$ /DMDBTDMA (80/20) and $(100 / 0)$ lamellar phases. (a) Identification of the lamellar phase domains of the $\mathrm{C}_{12} \mathrm{E}_{5} /$ DMDBTDMA 80/20 (black lines) and 100/0 (grey lines) systems. (b) X-ray scattering spectra of the $80 / 20$ (full line) and the $100 / 0$ (dashed line) lamellar phases at $\mathrm{C}_{12} \mathrm{E}_{5} / \mathrm{DMDBTDMA}$ weight fraction $\Phi=70 \%$ (inset: decomposition of the wide angle scattering part).

izes the geometry of amphiphilic molecules, is related to the shape of the aggregates formed in water: $\mathrm{P}=1$ for zero curvature objects like bilayers, $\mathrm{P}<1$ or $>1$ for direct or reverse aggregates respectively. $\mathrm{P}$ value of $\mathrm{C}_{12} \mathrm{E}_{5}$ is very sensitive to the hydration of polar heads and is modulated with temperature and concentration [10]. On the other hand, DMDBTDMA which is not soluble in water, and display a small polar head, is characterized by $\mathrm{P}$ $>1$. Increasing the amount of extractant molecules, bilayers aggregates are formed at higher water content than for the reference, which is consistent with the localization of DMDBTDMA within the bilayers.

The lamellar phases were characterized by X-ray scattering. Spectra (Fig. 2b) display the first and second order Bragg peaks at $\mathrm{q}_{0}$ and $2 \mathrm{q}_{0}$, characteristic of the lamellar phase. Moreover, a wide peak observed at large Qvector is analyzed using two GAUSSIAN signals roughly 

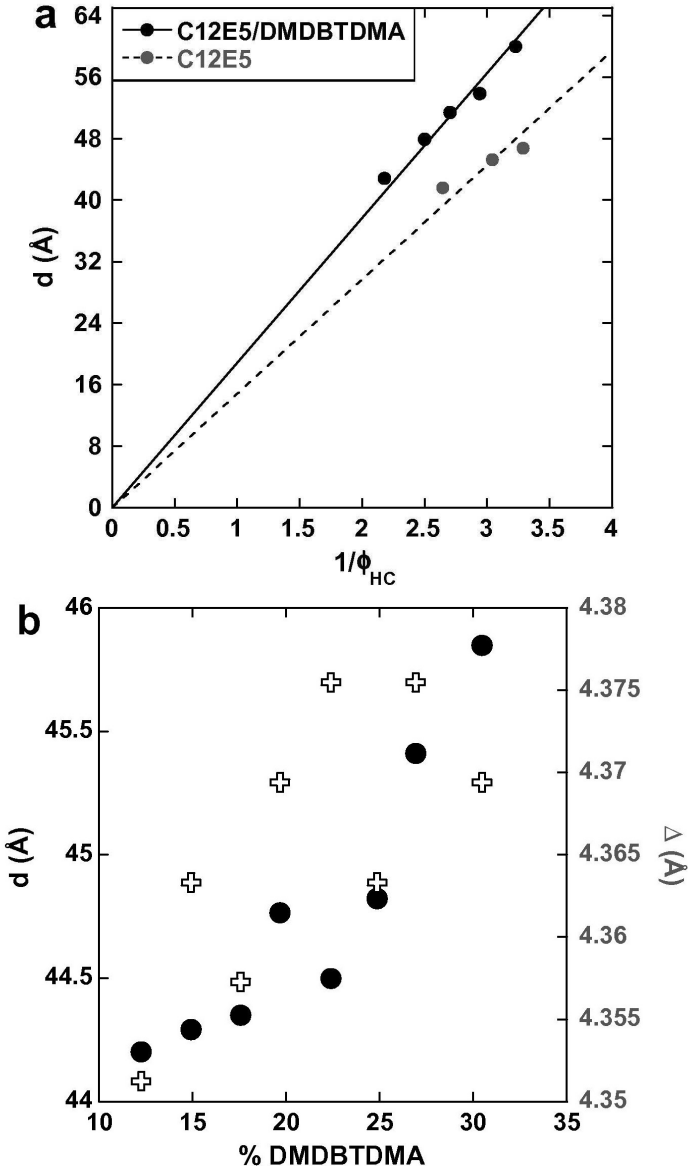

FIG. 3: (a) Dilution laws of $\mathrm{C}_{12} \mathrm{E}_{5} /$ DMDBTDMA 80/20 and 100/0 systems fitted according to Eq. (1). The range of $\Phi_{H C}$ is fixed by the stability phase boundaries and shows that the lamellar phase containing the extractant molecule can be slightly more diluted. (b) Evolution of the lamellar periodicity (full dots) and the characteristic distance of the bilayer liquid order (empty crosses) versus the molar percentage of DMDBTDMA into the bilayers of a lamellar phase at $\Phi=70 \%$.

centered at $\mathrm{q}_{w}=19.8 \mathrm{~nm}^{-1}$ and $\mathrm{q}_{b}=14.4 \mathrm{~nm}^{-1}$ (see inset of Fig. 2b). Both contributions can be assigned to the correlation distances characteristic of the liquid order in the aqueous phase [17], and within the bilayers [18, 19], respectively. The former is constant whatever the dilution. Defining d the periodicity of the lamellar phase obtained with the position of Bragg peaks $d=2 \Pi / q_{0}, \Phi_{H C}$ the volume fraction of DMDBTDMA and alkyl chains of $\mathrm{C}_{12} \mathrm{E}_{5}$ into the sample, and $\delta_{H C}$ the hydrocarbon thickness of bilayers, Fig. 3a displays the evolution of lamellar periodicities as a function of the inverse of $\Phi_{H C}$. As polyoxyethylene groups were considered to be in the aqueous region of the phase [20], we fitted our data using the following dilution law:

$$
d=\delta_{H C} \Phi_{H C}
$$

For calculations we used the following density values:
$d_{C 12}=0.803[21], d_{C 12 E 5}=0.963$ (from supplier) and $d_{D M D B T D M A}=0.906$ (measured). We can observe that the variation of lamellar periodicity $\mathrm{d}$ is not perfectly linear for the pure $\mathrm{C}_{12} \mathrm{E}_{5}$ as a function of $1 / \Phi_{H C}$. This was previously observed [22] and was attributed to a change in the bilayer thickness with dilution [23]. This can have different origins (evolution of polyoxyethylene heads conformation [24], interpenetration of alkyl chains [22], defects [25], ). For the $\mathrm{C}_{12} \mathrm{E}_{5}$ /DMDBTDMA 80/20 system, the evolution of $d$ appears more linear than for the $100 / 0$ system. It attests to a more classical behavior of the dilution law characterizing a lamellar phase with a constant thickness of the bilayers and weak bilayer undulations. Slopes of the linear fits in Fig. 3 indicate the average hydrocarbon bilayer thicknesses: $\delta_{H C}=14.0 \AA$ for $\mathrm{C}_{12} \mathrm{E}_{5}$ $(100 / 0)$, and $\delta_{H C}=18.8 \AA$ for $\mathrm{C}_{12} \mathrm{E}_{5}$ /DMDBTDMA $80 / 20$. The polar head area of $\mathrm{C}_{12} \mathrm{E}_{5}$ deduced from the geometrical relationship $A_{C 12 E 5}=2 . V_{H C} / \delta_{H C}$ is 50.1 $\AA^{2} /$ molecule, which is consistent with the data from the literature [26]. On Fig. 3b, the increase in the lamellar periodicity and in the averaged distance within the bilayers $\left(\Delta=2 \Pi / q_{b}\right)$ with the extractant molar fraction are displayed for $\Phi=70 \%$. Both evolutions confirm the insertion of DMDBTDMA into the bilayers. The $\Delta$ values range from that of pure surfactant $\left(\Delta_{S}=4.35 \AA\right)$ towards that of pure extractant $\left(\Delta_{E}=4.58 \AA\right)$ in their liquid state, respectively. Preliminary cryo-microscopic observations and temperature variation [27, 28] studies confirming also that no topological defects have to be taken into account along a dilution of our lamellar phase, the lamellar periodicity values were directly converted into hydrocarbon bilayer thicknesses using the dilution law (see Equation.2). Assuming a constant polar area per molecule at the hydrophilic/hydrophobic interface and an ideal mixing of both amphiphilic species the bilayer thickness can be expressed as a function of the repartition of extractant molecules between the interface and the aliphatic part of the bilayer:

$$
\delta_{H C}=\frac{V}{A}=2 \frac{(1-x) V_{C_{12}}+x V_{D M D B T D M A}}{(1-x) A_{C_{12} E_{5}}+x \kappa A_{D M D B T D M A}}
$$

with $V_{i}$ molecular volumes determined from density values, $A_{i}$ polar head areas $\left(A_{C 12 E 5}=50 \AA^{2} /\right.$ molecule, $A_{D M D B T D M A}=100 \AA^{2} /$ molecule $\left.[13,29]\right)$, x the molar fraction of DMDBTDMA among the organic components and $\mathrm{K}$ the fraction of DMDBTDMA participating to the interfacial area. Two extreme cases are plotted on Fig. 4 :

(i) $\mathrm{K}=0$, the extractant molecules are considered as buried within the bilayer and a significant increase in the bilayer thickness is expected.

(ii) $\mathrm{K}=1$, all extractant molecules participate to the interfacial area and a weak increase in the bilayer thickness should be observed. 


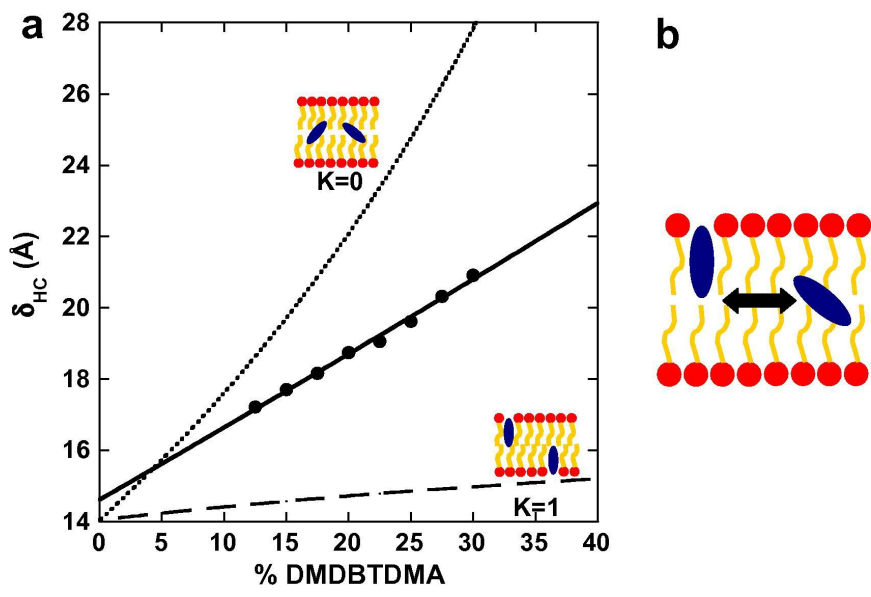

FIG. 4: (a) Evolution of the hydrocarbon bilayer thickness $\delta_{H} C$ versus the molar percentage of DMDBTDMA within the bilayers: the dotted and dashed lines display the models considering extractant molecules buried in the bilayer and at the interface of the bilayer, respectively. The experimental data (large dots), are fitted using Eq. 2. (b) Scheme of the equilibrium model proposed to adjust our data.

A good adjustment of our data requires $\mathrm{K}=0.44$ and $A_{C 12 E 5}=48 \AA^{2} /$ molecule. It validates our equilibrium model and indicates that $44 \%$ of extractant molecules are localized at interfaces whatever the ratio within the lamellar phase.

\section{$\mu$-Raman experiments}

In order to reinforce the model described in Eq. 2, we performed polarized $\mu$-Raman experiments on oriented domains of lamellar phases to qualitatively characterize the orientation of molecules. Planar and homeotrope oriented domains were localized by polarized light microscopy (see Fig. 5a) and their Raman spectra were obtained using the naturally polarized laser beam of the spectrometer (see Fig. 5). We simultaneously analyzed the stretching vibrations of $\mathrm{OH}$ groups between 3100 and $3700 \mathrm{~cm}^{-1}$, the stretching modes of $\mathrm{CH}_{2}$ and $\mathrm{CH}_{3}$ around $2900 \mathrm{~cm}^{-1}$, the characteristic bands of oxyethylene groups at 810 and $840 \mathrm{~cm}^{-1}$ [30], and the carbonyl stretching vibration at $1647 \mathrm{~cm}^{-1}$ [31]. Considering that the Raman signal is maximum for Raman tensors oriented parallel to the polarization of the incident laser beam [32], we measured different intensities as a function of the orientation of the lamellar phase. We found out that the orientation of $\mathrm{OH}$ and oxyethylenes bonds is preferentially in the direction perpendicular to the bilayers whereas the $\mathrm{CH}_{2}$ and $\mathrm{CH}_{3}$ tensors are oriented in the plane of the membrane. These orientations are consistent with the normal orientation of the surfactant molecules within the bilayers as expected. However, the carbonyl band from the polar head of the extractant molecules has the same intensity whatever the orientation of the system. It indicates that the orientation distribution of the carbonyls bonds is isotropic into the system. This is in accordance with the model of equilibrium for which half part of extractant molecules behave as oil, without preferential orientation within the bilayers.

\section{CONCLUSION}

In summary, we identified and characterized a mixed lamellar phase which allows us to investigate interfacial properties of extractant molecules (weak amphiphiles by definition that can play the role of co-surfactants). Results indicate that the insertion of DMDBTDMA in a $\mathrm{C}_{12} \mathrm{E}_{5}$ bilayer induces a decrease in the spontaneous curvature of the interface, by establishing equilibrium of extractant molecules within the bilayer: roughly, half of the extractant is buried within the organic part in the membrane, whereas the other half is adsorbed at the bilayer/water interface. As we demonstrate that this type of lyotropic lamellar phase is a good support system for tracking a complexing extractant molecule at a liquid/liquid interface, further works are currently in progress to study the effect of ion complexation reaction on the interfacial properties. Moreover, we think that the approach developed in this Letter is not only interesting in the extraction field but in a more general way to study partitioning of hydrophobic molecules (cholesterol, drugs, . . .) inserted into bilayers.

\section{ACKNOWLEDGEMENTS}

We would like to thank Pr. T. Zemb for fruitful and stimulating discussions, Bruno CORSO for his assistance in SAXS experiments and Dr. R. Leparc for preliminary measurements in polarized Raman spectroscopy. This work was supported by the European ACSEPT network.

[1] H.A. Scheidt and D. Huster. The interaction of small molecules with phospholipid membranes studied by $1 \mathrm{H}$ NOESY NMR under magic-angle spinning1. Acta Pharmacologica Sinica, 29(1):35-49, 2008.

[2] T.J. McIntosh. The 2004 Biophysical Society-Avanti Award in Lipids address: roles of bilayer structure and elastic properties in peptide localization in membranes. Chemistry and physics of lipids, 130(2):83-98, 2004.

[3] J.A. Killian. Hydrophobic mismatch between proteins and lipids in membranes. Biochimica et Biophysica Acta (BBA)-Reviews on Biomembranes, 1376(3):401415, 1998.

[4] S.D. Zucker, W. Goessling, E.J. Bootle, and C. Sterritt. Localization of bilirubin in phospholipid bilayers by par- 

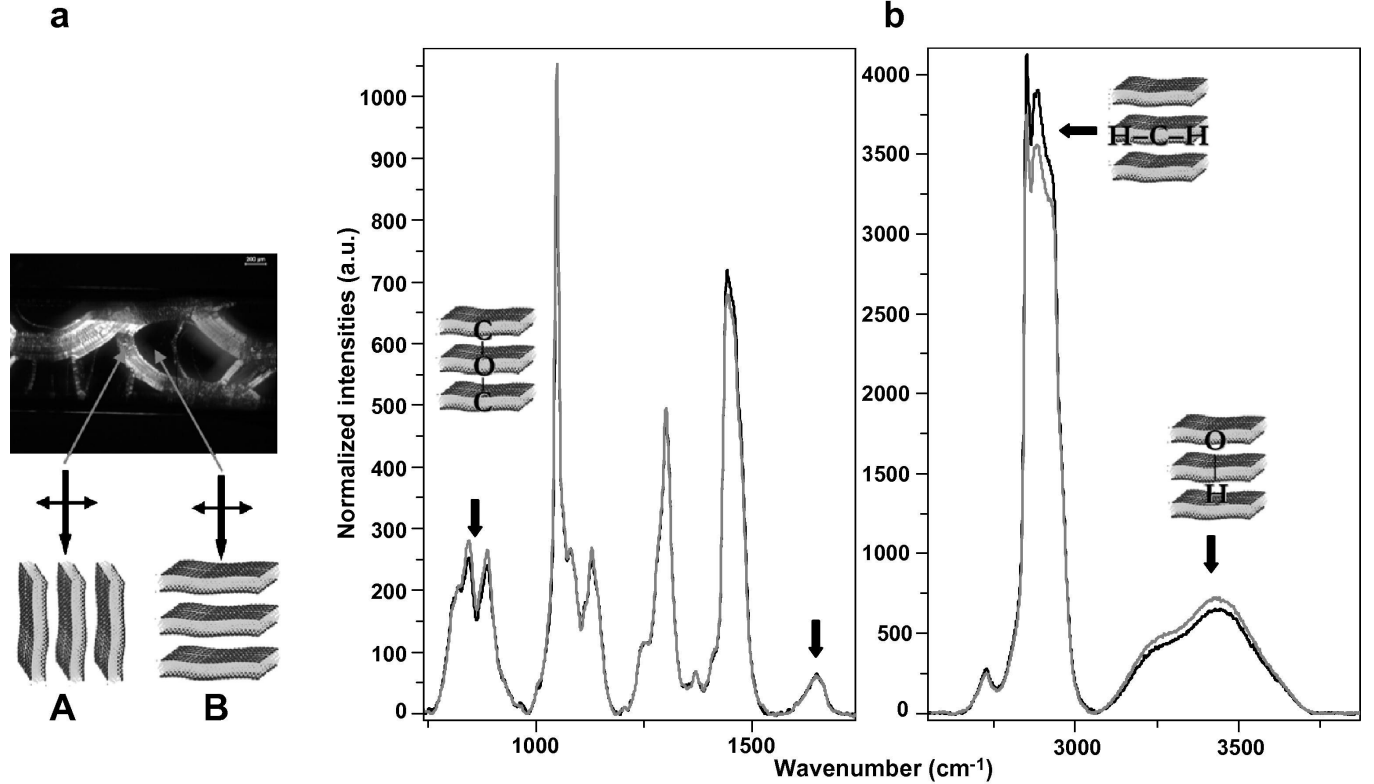

FIG. 5: $\mu$-Raman spectroscopy performed on oriented lamellar phases. (a) Identification of oriented domains by polarized light microscopy. Spectra are performed on two kinds of configurations: (A) with the laser beam polarization oriented perpendicular to the bilayers, on planar domains and (B) with the laser beam polarization oriented parallel to the bilayers, on homeotropic domains. (b) Raman spectra of the $\mathrm{C}_{12} \mathrm{E}_{5}$ /DMDBTDMA 80/20 oriented lamellar phase for configurations A (grey line) et $\mathrm{B}$ (black line).

allax analysis of fluorescence quenching. Journal of Lipid Research, 42(9):1377, 2001.

[5] I. Martin, E. Goormaghtigh, and J. M. Ruysschaert. Attenuated total reflection ir spectroscopy as a tool to investigate the orientation and tertiary structure changes in fusion proteins. Biochimica et Biophysica Acta (BBA) - Biomembranes, 1614(1):97 - 103, 2003. Membrane Fusion.

[6] EZ Radlinska, T. Gulik-Krzywicki, F. Lafuma, D. Langevin, W. Urbach, and CE Williams. Modification of the lamellar phase in $\mathrm{C} 12 \mathrm{E} 5 /$ water system by a random hydrophilic-hydrophobic polyelectrolyte. Journal de Physique II, 7(10):1393-1416, 1997.

[7] R. Vijayan and P.C. Biggin. A Steroid in a Lipid Bilayer: Localization, Orientation, and Energetics. Biophysical journal, 95(7):L45-L47, 2008.

[8] A. Aroti, E. Leontidis, M. Dubois, and T. Zemb. Effects of monovalent anions of the Hofmeister series on DPPC lipid bilayers part I: swelling and in-plane equations of state. Biophysical journal, 93(5):1580-1590, 2007.

[9] K.L. Nash and G.J. Lumetta. Advanced Separation Techniques for Nuclear Fuel Reprocessing and Radioactive Waste Treatment. 2010.

[10] D.J. Mitchell, G.J.T. Tiddy, L. Waring, T. Bostock, and M.P. McDonald. Phase behaviour of polyoxyethylene surfactants with water. Mesophase structures and partial miscibility (cloud points). Journal of the Chemical Society, Faraday Transactions 1, 79(4):975-1000, 1983.

[11] R. Strey, R. Schom

"acker, D. Roux, F. Nallet, and U. Olsson. Dilute lamellar and L3 phases in the binary water-C12E5 system. $J$. Chem. Soc. Faraday Trans, 86:2253-2261, 1990.

[12] J. Szymanowski. Kinetics and interfacial phenomena. Solvent Extraction and Ion Exchange, 18(4):729-751,
2000.

[13] C. Erlinger, D. Gazeau, T. Zemb, C. Madic, L. Lefrançois, M. Hebrant, and C. Tondre. Effect of nitric acid extraction on phase behavior, microstructure and interactions between primary aggregates in the system dimethyldibutyltetradecylmalonamide (DMDBTDMA)/n-dodecane/water: a phase analysis and small angle x-ray scattering (SAXS) characterisation study. Solvent Extraction and Ion Exchange, 16(3):707-738, 1998.

[14] Y. Li, R. Beck, T. Huang, M.C. Choi, and M. Divinagracia. Scatterless hybrid metal-single-crystal slit for smallangle X-ray scattering and high-resolution X-ray diffraction. Journal of Applied Crystallography, 41(6):11341139, 2008.

[15] G.Y.S. Chan, M.G.B. Drew, M.J. Hudson, P.B. Iveson, J.O. Liljenzin, M. Skålberg, L. Spjuth, and C. Madic. Solvent extraction of metal ions from nitric acid solution using N, N-substituted malonamides. Experimental and crystallographic evidence for two mechanisms of extraction, metal complexation and ion-pair formation. Journal of the Chemical Society, Dalton Transactions, 1997(4):649-660, 1997.

[16] J.N. Israelachvili, D.J. Mitchell, and B.W. Ninham. Theory of self-assembly of hydrocarbon amphiphiles into micelles and bilayers. Journal of the Chemical Society, Faraday Transactions 2, 72:1525-1568, 1976.

[17] G. Hura, J.M. Sorenson, R.M. Glaeser, and T. HeadGordon. A high-quality x-ray scattering experiment on liquid water at ambient conditions. The Journal of Chemical Physics, 113:9140, 2000.

[18] T.T. Mills, S. Tristram-Nagle, F.A. Heberle, N.F. Morales, J. Zhao, J. Wu, G.E.S. Toombes, J.F. Nagle, and G.W. Feigenson. Liquid-liquid domains in bilayers 
detected by wide angle x-ray scattering. Biophysical journal, 95(2):682-690, 2008.

[19] T.T. Mills, G.E.S. Toombes, S. Tristram-Nagle, D.M. Smilgies, G.W. Feigenson, and J.F. Nagle. Order parameters and areas in fluid-phase oriented lipid membranes using wide angle x-ray scattering. Biophysical journal, 95(2):669-681, 2008.

[20] S.S. Funari and G. Rapp. X-ray Studies on the C12EO2/Water System. J. Phys. Chem. B, 101(5):732739, 1997.

[21] C. Tanford. Micelle shape and size. The Journal of Physical Chemistry, 76(21):3020-3024, 1972.

[22] E. Kurtisovski, N. Taulier, R. Ober, M. Waks, and W. Urbach. Molecular origin of model membrane bending rigidity. Physical review letters, 98(25):258103, 2007.

[23] E. Ruckenstein and M. Manciu. On the stability of lyotropic lamellar liquid crystals and the thicknesses of their lamellae. Langmuir, 17(18):5464-5475, 2001.

[24] A. Tonegawa, K. Ohno, H. Matsuura, K. Yamada, and T. Okuda. A Combined Raman and Deuterium NMR Spectroscopic Study on the Molecular and Phase Structure of a Nonionic Surfactant C12E5- Water System. J. Phys. Chem. B, 106(51):13211-13223, 2002.

[25] S.S. Funari, M.C. Holmes, and G.J.T. Tiddy. Intermediate lyotropic liquid crystal phases in the C16EO6/water system. The Journal of Physical Chemistry, 98(11):30153023, 1994.

[26] M.J. Rosen, A.W. Cohen, M. Dahanayake, and X.Y. Hua. Relationship of structure to properties in surfactants. 10. Surface and thermodynamic properties of 2- dodecyloxypoly (ethenoxyethanol) s, C12H25 (OC2H4) $\mathrm{xOH}$, in aqueous solution. The Journal of Physical Chemistry, 86(4):541-545, 1982.

[27] O. Dhez, S. K

"onig, D. Roux, F. Nallet, and O. Diat. Lamellar-tonematic phase transition in a lipid-surfactant mixture. The European Physical Journal E: Soft Matter and Biological Physics, 3(4):377-388, 2000.

[28] P. Moreau, L. Navailles, J. Giermanska-Kahn, O. Mondain-Monval, F. Nallet, and D. Roux. Dislocation-loop-mediated smectic melting. EPL (Europhysics Letters), 73:49, 2006.

[29] P. Bauduin, F. Testard, L. Berthon, and T. Zemb. Relation between the hydrophile/hydrophobe ratio of malonamide extractants and the stability of the organic phase: investigation at high extractant concentrations. Physical Chemistry Chemical Physics, 9(28):3776-3785, 2007.

[30] V.S. Marinov, Z.S. Nickolov, and H. Matsuura. Raman Spectroscopic Study of Water Structure in Aqueous Nonionic Surfactant Solutions. J. Phys. Chem. B, 105(41):9953-9959, 2001.

[31] V.A. Shashilov, V.V. Ermolenkov, T.G. Levitskaia, and I.K. Lednev. Metal ion binding by a bicyclic diamide: Deep UV Raman spectroscopic characterization. J. Phys. Chem. A, 109(32):7094-7098, 2005.

[32] M. Tanaka and RJ Young. Review Polarised Raman spectroscopy for the study of molecular orientation distributions in polymers. Journal of Materials Science, 41(3):963-991, 2006. 